\title{
Assessment of knowledge and attitudes of married women on maternal and newborn health (MNH) in selected union councils of project districts
}

Pakistan Initiative for Mothers and Newborns (PAIMAN)

Follow this and additional works at: https://knowledgecommons.popcouncil.org/departments_sbsr-rh

Part of the Demography, Population, and Ecology Commons, Family, Life Course, and Society Commons, Gender and Sexuality Commons, International Public Health Commons, Maternal and Child Health Commons, Medicine and Health Commons, and the Women's Health Commons How does access to this work benefit you? Let us know!

\section{Recommended Citation}

Pakistan Initiative for Mothers and Newborns (PAIMAN). 2008. "Assessment of knowledge and attitudes of married women on maternal and newborn health (MNH) in selected union councils of project districts." Islamabad: Population Council. 
Assessment of Knowledge \& Attitudes of Married Women on Maternal \& Newborn Health (MNH) in selected Union Councils of Project districts 


\section{Assessment of Knowledge \& Attitudes of Married Women on Maternal \& Newborn Health (MNH) in selected Union Councils of Project districts}




\section{(P) Population Council}

The Population Council, an international, non-profit, non-governmental organization established in 1952, seeks to improve the well-being and reproductive health of current and future generations around the world and to help achieve a humane, equitable, and sustainable balance between people and resources.

The Council analyzes population issues and trends; conducts research in the reproductive sciences; develops new contraceptives; works with public and private agencies to improve the quality and outreach of family planning and reproductive health services; helps governments design and implement effective population policies; communicates the results of research in the population field to diverse audiences; and helps strengthen professional resources in developing countries through collaborative research and programs, technical exchanges, awards, and fellowships.

\section{For inquiries, please contact:}

\section{Population Council}

\#7, Street 62, F-6/3, Islamabad, Pakistan

Tel: 92512277439

Fax: 92512821401

Email: info@pcpak.org

web: http://www.popcouncil.org

Layout \& Design : Ali Ammad

Printed by: Crystal Printers, Islamabad

\section{Disclaimer:}

"This study/report is made possible by the generous support of the American people through the United States Agency for International Development (USAID). The contents are the responsibility of JSI Research \& Training Institute, Inc. and do not necessarily reflect the views of USAID or the United States Government." 


\section{Table of Content}

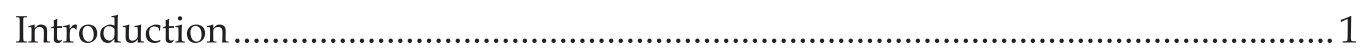

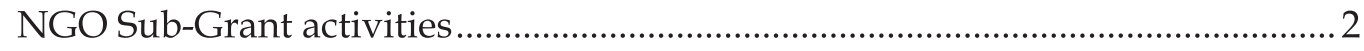

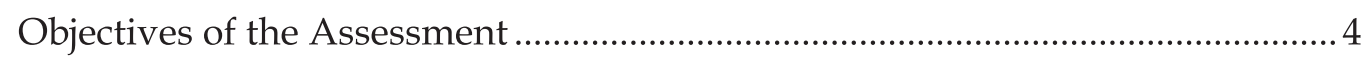

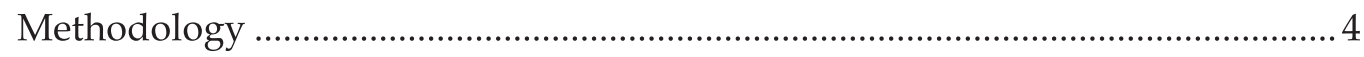

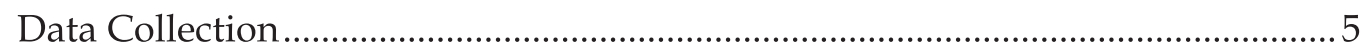

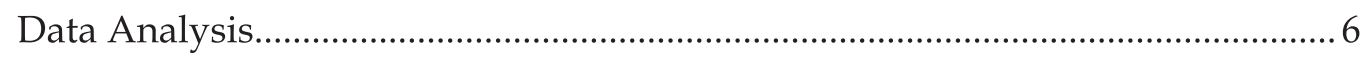

Calculation of Averages and Confidence Intervals: ....................................... 6

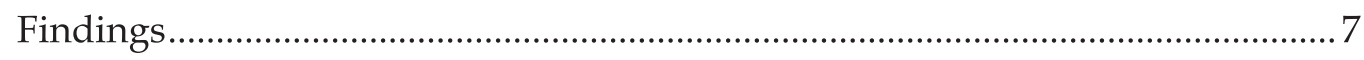

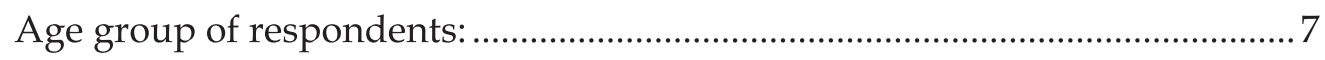

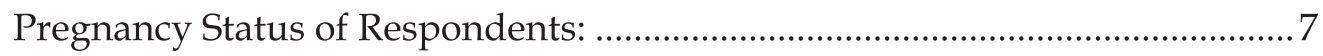

Level of Knowledge about pregnancy care ................................................... 7

Level of Knowledge about Delivery .................................................................. 10

Level of Knowledge about Post Natal Care .................................................... 11

Level of Knowledge about Newborn Care....................................................... 13

Level of Knowledge about 3 or more danger signs (Pregnancy,

Delivery, Postnatal, and Newborn)................................................................. 15

Level of belief that one or more danger signs do not require medical

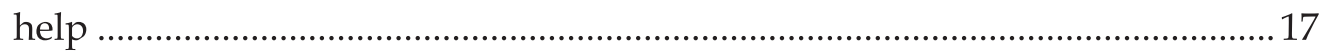

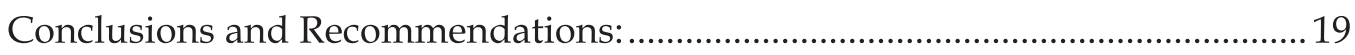





\section{Introduction}

Pregnancy-related conditions, including dysfunctional labor, hemorrhage, infection, toxemia, and unsafe abortion, are the leading cause of death among women of reproductive age in many developing countries; the World Health Organization estimates that 585,000 women die from pregnancy-related conditions each year (Population Council). Three delays model describes barriers in addressing maternal health problems. First delay occurs at home when decision to go for health care is not taken at the right time, due mainly to the lack of knowledge of the household regarding MNH issues. This report describes the process and results of community surveys carried out in the selected union councils of five Districts i.e. Sukkur, Jhelum, Lasbella, Rawalpindi and DG khan. Overall goal of this activity is to assess the knowledge and attitude of married women regarding $\mathrm{MNH}$ issues.

The Pakistan Initiative for Mothers and Newborns (PAIMAN) is a five-year project funded by the United States Agency for International Development (USAID). Its goal is to reduce maternal and newborn mortality in Pakistan, through viable and demonstrable initiatives and capacity building of existing programs and structures within health systems and communities to ensure improvements and supportive linkages in the continuum of health care for women from the home to the hospital.

Of the five strategic objectives (SO) of PAIMAN, SO1 is to increase awareness and promote positive maternal and neonatal health behaviors. For that PAIMAN is implementing a Communication, Advocacy and Mobilization (CAM) strategy to increase women's and their family's knowledge and awareness on harmful practices and for improved health behavior that will promote birth preparedness, skilled attendance at delivery and appropriate antenatal care; create an enabling environment that supports the survival of women and newborns; and create a culture of shared responsibility for $\mathrm{MNH}$.

One of the approaches adopted by PAIMAN for the above strategy is to implement an NGO sub-granting mechanism. The purpose of the grants program is to develop a community-level infrastructure that is able to implement community-based interventions promoting use of maternal health, newborn care and contraceptive services as well as reduce the barriers affecting the use of such services. These NGOs work with local community in specific villages of the 
Project districts and develop community-based plans that address unique issues of each community.

A Mid-Term Review (MTR) was carried out to review the sub-grant activities implemented by the NGOs. Another assessment is planned for reviewing the outcome of this component of PAIMAN.

\section{NGO Sub-Grant activities}

The NGOs sub-granted by PAIMAN work primarily in selected villages that are not covered by LHW program. Their activities are targeted to raising awareness of maternal and newborn health among the married women in particular and the community in general. These interventions are implemented in a phased manner. It is expected that these interventions will have positive outcomes (i.e. increased MNH knowledge and awareness) among the beneficiaries in the short run gradually leading to positive outcomes among married women and ultimately among the community at large. The Community Health Workers (CHWs) are recruited for raising the $\mathrm{MNH}$ awareness among the eligible women and community mobilization in the target population. Each $\mathrm{CHW}$ covers almost 1,000 populations in the area. These $\mathrm{CHWs}$ also maintain a register where all the data related to women and newborn is available. These CHWs also maintain the Committees Health Group members lists. The concerned NGOs also maintain the list of the members of the health committees. Using these two sources, the current assessment was conducted.These NGOs were provided seed money for one year to start their activities from July 2006.A Mid-Term Review (MTR) was carried out to review the sub-grant activities implemented by the NGOs. Another assessment is planned for reviewing the outcome of this component of PAIMAN.

This report describes the process and results of community surveys carried out in the selected union councils of District Sukkur, Jhelum, Lasbella, Rawalpindi and Dera Ghazi Khan. Overall goal of this activity was to assess the knowledge and attitude of married women regarding $\mathrm{MNH}$ issues.

The matrix below provides the framework of NGO sub-grant activities, their immediate outputs, the intermediate outcomes and the long-term results. The activities and figures in the matrix are examples from one NGO sub-grant agreement and were tailored to the individual NGO for the assessment purpose. It was expected that through these NGO activities initially there would be increased knowledge and awareness among the beneficiaries of the NGO 
activities (i.e. Community Health Group members, participants of seminar); these beneficiaries will then act as the change agents within the community and will ultimately propagate positive attitude and behavior change among the target population (i.e. married women/mothers and their families) and, in due course, among the community at large.

\begin{tabular}{|c|c|c|c|c|}
\hline & NGO Sub-Grant Activity & $\begin{array}{c}\text { Output } \\
\text { (Immediate) }\end{array}$ & $\begin{array}{c}\text { Outcome } \\
\text { (Intermediate) }\end{array}$ & $\begin{array}{c}\text { Result } \\
\text { (Long term) }\end{array}$ \\
\hline - & $\begin{array}{l}\text { Creation of } 20 \text { Health } \\
\text { Groups of } 6-8 \text { members } \\
\text { each }\end{array}$ & $\begin{array}{l}120-160 \\
\text { female/male } \\
\text { members with MNH } \\
\text { knowledge }\end{array}$ & $\begin{array}{l}\text { Increased awareness } \\
\text { among participants } \\
\text { (direct beneficiaries) }\end{array}$ & $\begin{array}{l}\text { Increase in ANC/PNC } \\
\text { Increase in CPR }\end{array}$ \\
\hline घ & $8 \mathrm{MNH}$ seminars & $\begin{array}{l}400 \quad \text { participants } \\
\text { receiving } \mathrm{MNH} \\
\text { messages }\end{array}$ & $\begin{array}{l}\text { (After a time lag) } \\
\text { Increased awareness in } \\
\text { the community }\end{array}$ & $\begin{array}{l}\text { Increase in timely } \\
\text { referrals }\end{array}$ \\
\hline - & 4 theatre performances & & & Birth preparedness \\
\hline घ & $\begin{array}{l}\text { MNH messages in schools } \\
\text { (teachers/students) }\end{array}$ & & & Skilled attendance at \\
\hline - & $\begin{array}{l}\text { Mother's day celebration } \\
\text { Sports events }\end{array}$ & & & delivery \\
\hline - & Quiz competitions & & & \\
\hline - & $\begin{array}{l}\text { Target Group Meetings } \\
\text { through } 20 \mathrm{CHWs}\end{array}$ & & & \\
\hline - & 30 TBAs orientation & & & \\
\hline - & $\begin{array}{l}\text { Community revolving fund } \\
\text { for emergency situations }\end{array}$ & & & \\
\hline
\end{tabular}

\section{A. Rationale for the assessment}

The local NGOs/CBOs had been implementing the community awareness activities in the selected union councils of the districts. Since long term results were not apparent, it was imperative to assess the midterm outcomes of these community mobilization and awareness activities. So to understand whether these NGO sub-grant activities were producing the desired outcomes, it was necessary to carryout a community survey that targeted $\mathrm{MNH}$ awareness/attitude changes in the women of the community. The assessment would be helpful in planning or implementing the component activities in a more improved way. 


\section{Objectives of the Assessment}

1. To assess the improvement in the level of $\mathrm{MNH}$ knowledge and awareness among married women in intervention villages

2. To assess the attitudes of married women regarding $\mathrm{MNH}$ issues

\section{Methodology}

Lot Quality Assurance Sampling (LQAS) technique was applied to measure the level of progress toward desirable change among the married women in the villages where the NGOs work. Therefore, the study population for this assessment were married women in the intervention areas where awareness raising and community mobilization activities had been implemented.

\section{Sampling Technique:}

One (or two) union councils, where the NGO had completed the awareness campaigns and community mobilization activities were selected. Within that UC, using the information collected in the registers of CHWs, 19 married women were randomly selected. Firstly, all the CHWs were listed and number of their registered women was put in front of each CHW. Sampling interval was calculated by dividing the total number of covered women by all CHWs by 19 . First women is selected randomly within the sampling interval. Subsequent 18 samples were collected by adding sample interval to first random number.

Following union councils in three districts were selected:

\begin{tabular}{lllc} 
& & & \multicolumn{2}{c}{ Married Women of Reproductive } \\
District & Selected UC & Tehsil & 1951 \\
Sukkur & Long Bhatti & Rohri & 4400 \\
Jhelum & Chak 45\&Chak 49 & Jhelum & 1576 \\
Lasbella & Pathra \& Berot & Hub & 3800 \\
Rawalpindi & Sarai Kala & Taxilla & 5000 \\
DG Khan & Bahadur Garh & DG Khan \\
\hline
\end{tabular}

\section{Data Collection Tool:}

These individuals were interviewed to assess their knowledge on danger signs of pregnancy, delivery, post-partum and newborns. A pre-structured, quantitative questionnaire was developed to collect the information. 


\section{Data Collection Technique:}

A team of two female interviewers was hired locally. Married women were interviewed face to face and questionnaire was filled. Interviewers were given an orientation regarding sampling, location and identification of houses in the community and questionnaire.

LQAS table was used to determine whether the level of knowledge among the particular target group meets the Project's expectations or not

The attached questionnaire was developed based on PAIMAN's Baseline Survey questionnaire. Questions on the following are included in the questionnaire:

- Household information/Background information

- Knowledge of danger signs of pregnancy, delivery, post-partum and newborn

- Awareness of birth preparedness: emergency funds, emergency transport arrangement and identification of health facility

- Awareness of skilled delivery services

- Awareness of newborn bathing

- Awareness of TT immunization during pregnancy

- Awareness of giving colustrum to newborns

Population Council took the lead role in the implementation and analysis of the assessment study; ISI provided all the necessary facilitation for that purpose.

\section{Data Collection}

The Population Council arranged local interviewers. Staff from the district health office and the concerned NGO was also involved as observer for this purpose. For each district, two interviewers were hired for three days. On day one, they were trained/oriented about the assignment and questionnaire. Data collection was carried out for the next two days. 


\section{Data Analysis}

Hand tabulation of the data was done, so as to reduce any dependency on developing new computer program by the District Health Office or the NGOs for any future assessment/monitoring activity using LQAS technique. The level of knowledge/attitude among a particular group was compared with the "decision rule" using the LQAS table.

LQAS technique allowed testing whether a pre-defined level of expected outcome had been achieved in the target village or not. While conducting these surveys in the respective districts, we have used the results of the baseline survey to determine the expected level of outcomes in the target villages where the NGO sub-grant activities were implemented. Although the findings given below were for the whole district, we tested it in the target UC/UCs.

The expected levels of outcomes were different for each district and had been set on the basis of the baseline results for the corresponding district and in consultations with the concerned NGO working in that district. These expected levels of outcomes determined the "decision rule" for each indicator that was assessed through the survey using LQAS.

Later on the data was also entered and analyzed using SPSS 13.0 package to get aggregates across districts, so it provided the average of each indicator for 5 districts with confidence intervals.

\section{Calculation of Averages and Confidence Intervals:}

Average of an indicator for all (5) districts is calculated by giving it weight according to target population. It means that the covered population of CHWs must be known. So that the resultant finding of an indicator out of 19 is titrated against the total target population (in this case MWRA registered by CHWs). 


\section{Findings}

\section{Age group of respondents:}

In five districts a total number of 95 women were interviewed. Among all the respondents (95) in 5 districts, slightly half were in the age group of 25 to 34 years whereas remaining (39\%) were more than 34 years of age and 10\% were below 25 years of age. A district wise distribution shows above two third (15) of respondents in Lasbella were among 25 to 34 years age group.

Table 1: Age group of Respondents

\begin{tabular}{lccccc|c}
\hline \multirow{2}{*}{ Age of respondents } & \multicolumn{7}{c}{ Name of district } \\
\cline { 2 - 7 } & Jehlum & Lasbala & Sukkur & Rawalpindi & DG Khan & Total \\
\hline 25 years & 2 & 1 & 1 & 1 & 5 & 10 \\
25 to 34 years & 7 & 15 & 7 & 11 & 8 & 48 \\
$35+$ years & 10 & 3 & 11 & 7 & 6 & 37 \\
Total & 19 & 19 & 19 & 19 & 19 & 95 \\
\hline
\end{tabular}

\section{Pregnancy Status of Respondents:}

About a quarter (23) of respondents were pregnant at the time of interview.

\section{Table 2: Current Pregnancy Status}

\begin{tabular}{llccc}
\hline District & & Are you currently pregnant & \multicolumn{2}{c}{ Total } \\
\hline \multirow{3}{*}{ Name of district } & Jehlum & Yes & No & \\
& Lasbala & 4 & 15 & $\mathbf{1 9}$ \\
& Sukkur & 3 & 16 & $\mathbf{1 9}$ \\
& RPindi & 6 & 13 & $\mathbf{1 9}$ \\
& DG Khan & 5 & 14 & $\mathbf{1 9}$ \\
Total & & 5 & 14 & $\mathbf{1 9}$ \\
\hline
\end{tabular}

\section{Level of Knowledge about pregnancy care}

Antenatal care is a key element of programs to improve the health of mothers and newborns. One of the objectives of the NGOs working in the visited areas was to improve the attitude and knowledge of married women and mothers regarding pregnancy and antenatal care. Overall, respondents had satisfactory level of knowledge and a positive attitude regarding pregnancy care, although there were some important gaps e.g. timings of first ANC visit and total ANC visits during a pregnancy. 
Figure 1: Attitude of women regarding need for ANC during pregnancy

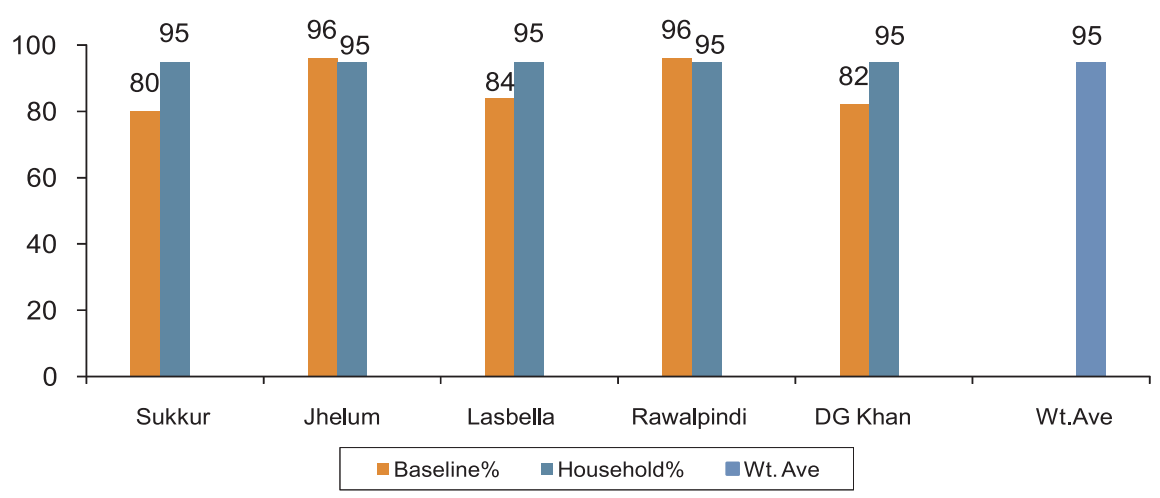

Majority of women in five districts knew proper time to initiate visiting for ANC. Compared to baseline level; there has been a marked improvement across five districts. As compared to other districts Lasbella and DG Khan scored low where half of women who know correctly that the first ANC visit should be carried within first trimester of pregnancy. Lasbella and DG Khan are below weighted average of 5 districts compared to other 3 districts, which scored high.

Figure 2: Knowledge regarding first ANC visit within 3 months of pregnancy

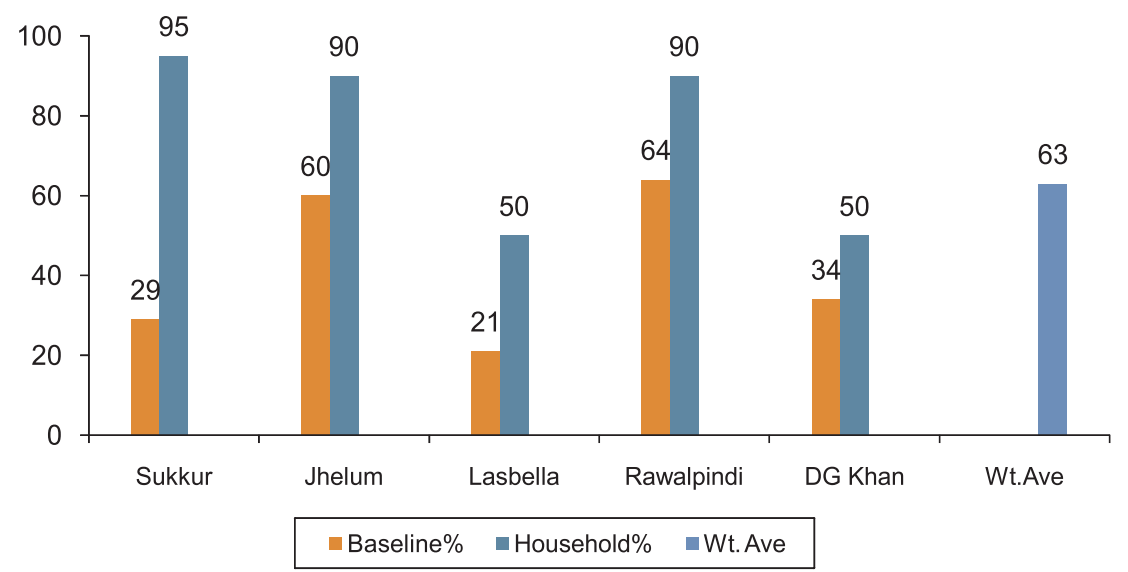

World Health Organization recommends at least 4 ANC visits by a pregnant woman during 9 months of her pregnancy. Current estimates for Pakistan regarding ANC visits by pregnant women indicate low percentages (UNICEF, WHO 2001). During assessment in 5 PAIMAN districts, overall majority of women had correct knowledge about number of ANC visits required during the pregnancy. LQAS findings show that there has been a marked improvement compared to baseline levels. Compared to other 3 districts, women in Lasbella 
and DG Khan need more emphasis on this awareness, which are below the weighted average for 5 districts.

Figure 3: Knowledge about 4 or more ANC Checkups during pregnancy

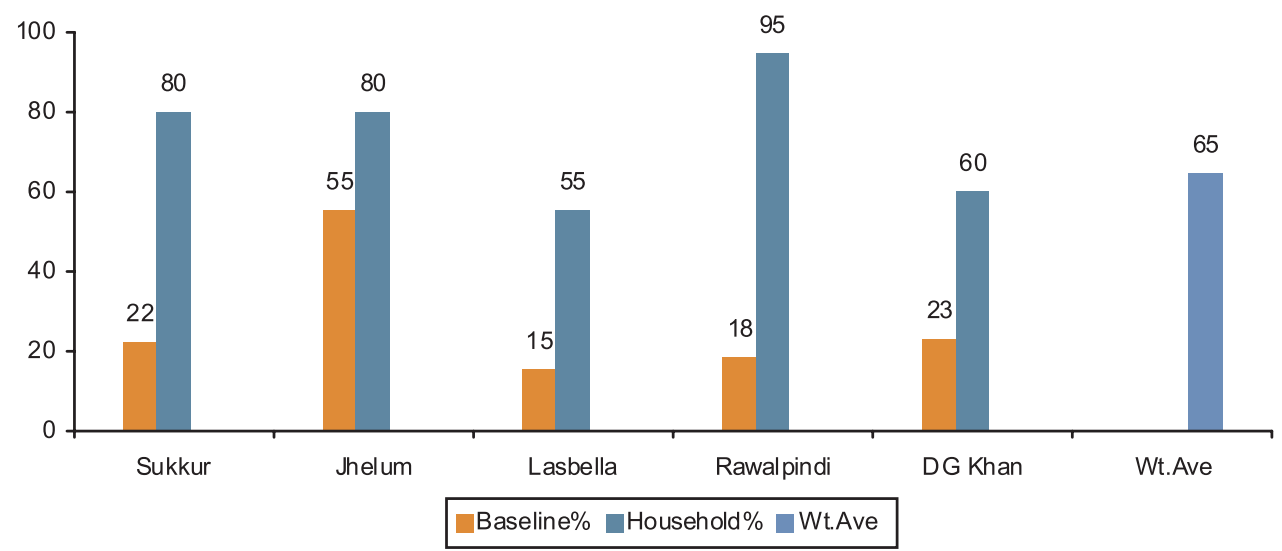

The T.T. immunization protects the mother and the baby against tetanus, a life threatening disease. All respondents mentioned that a woman should have TT shots during pregnancy. This shows a positive attitude for TT immunization during pregnancy.

Most of the women across 5 districts knew that TT immunization protects mother and newborn from tetanus (or from some disease). All women in five districts responded that woman should have TT shots during pregnancy.

Figure 4: TT Shots in pregnancy

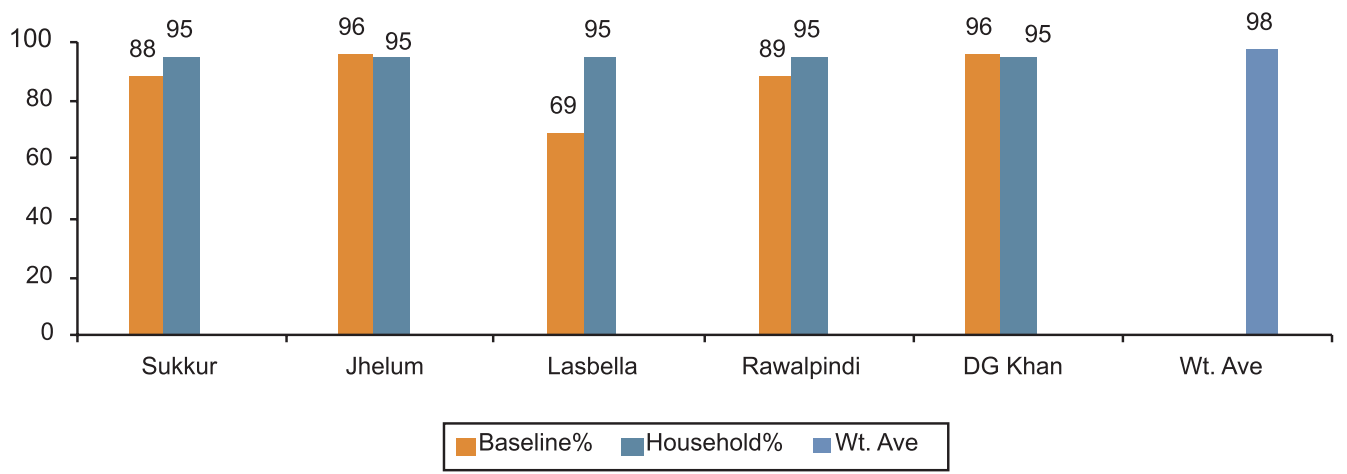

Anemia is a very common condition during pregnancy. Anemia during pregnancy leads to pre-mature delivery, still birth, and low birth weight babies. Severe anemia can lead to the death of the woman during childbirth. LQAS findings show that almost all women showed a positive attitude towards the intake of iron tablets during pregnancy. Most of the women were also aware regarding the benefits of iron tablets. Almost a third of women reported that iron tablets are used to reduce weakness while slightly less than half thought that iron therapy is used to improve anaemia and health of the women. 
Figure 5: Positive attitude regarding Iron Tablets in pregnancy

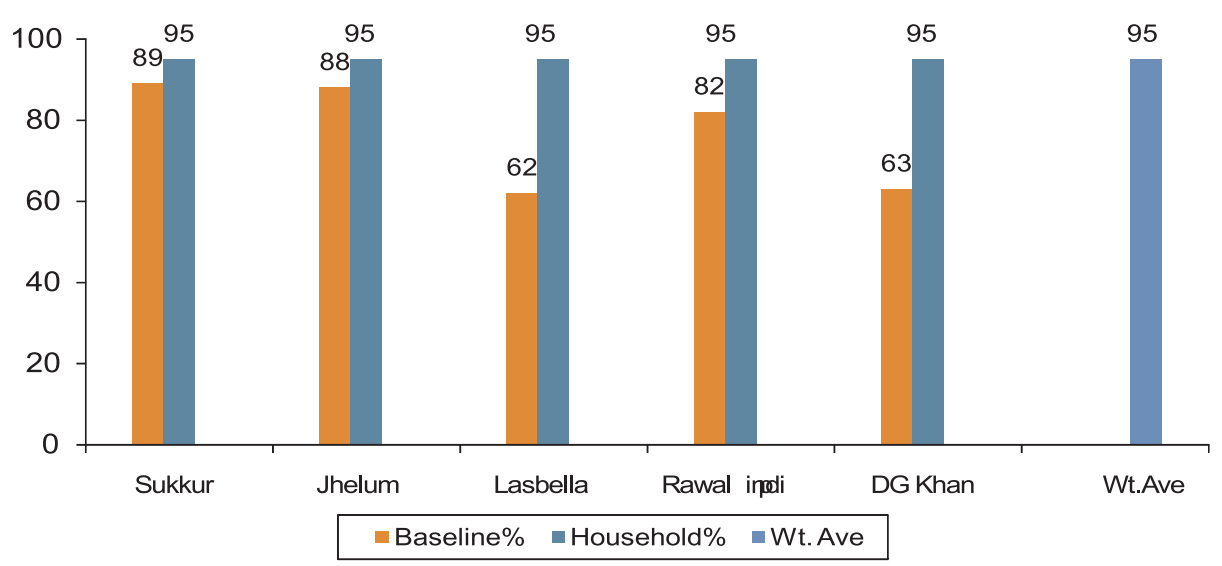

Table 2: Purpose of Iron tablets

\begin{tabular}{|c|c|c|}
\hline Response & Frequency & Percent \\
\hline Correct & 74 & 78 \\
\hline Wrong & 21 & 22 \\
\hline Total & 95 & 100.0 \\
\hline
\end{tabular}

\section{Level of Knowledge about Delivery}

PAIMAN project seeks to change the attitude of women towards safe delivery practices by skilled birth attendants. Baseline findings were very high for women's attitude towards place of delivery, delivery by an SBA and regarding delivery arrangements. By the end of current assessment, women's attitudes towards delivery by a skilled birth attendant and in a hospital had further strengthened in five districts. 
Figure 6: Attitude regarding Delivery by Skilled Birth Attendant

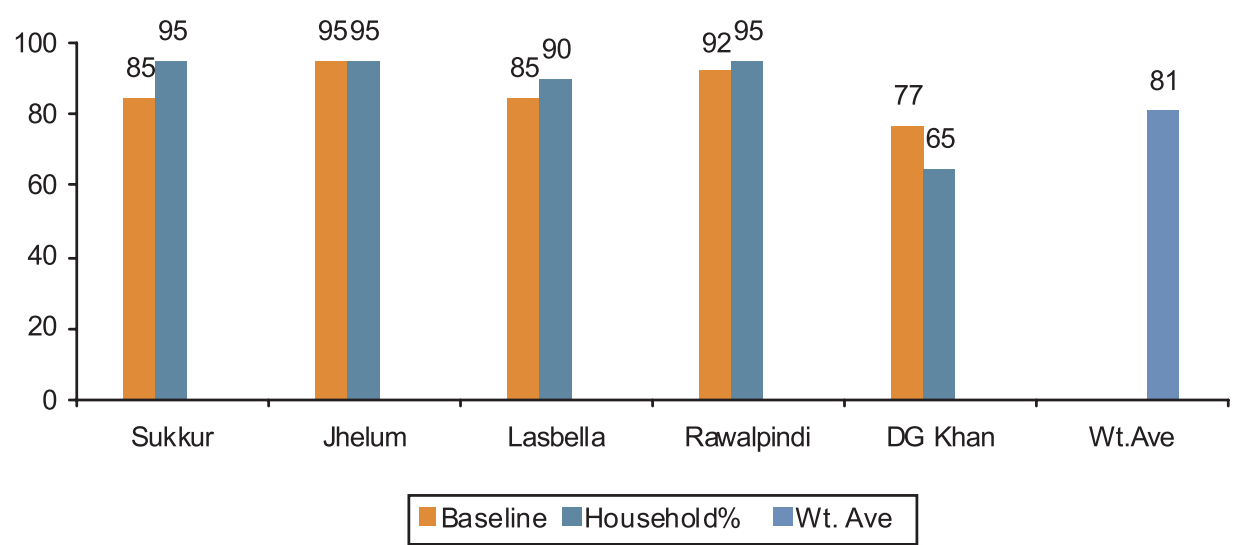

Women were also asked to report delivery arrangements made for the safety of mother and newborn. Majority of women in Sukkur were able to tell three or more delivery arrangements while only less than a quarter in Jhelum, Rawalpindi, DG Khan and a third in Lasbella were able to correctly tell 3 or more delivery arrangements. All five districts showed level of knowledge above the total weighted average for 5 districts.

\section{Figure 7: Knowledge about 3 or more Delivery arrangements}

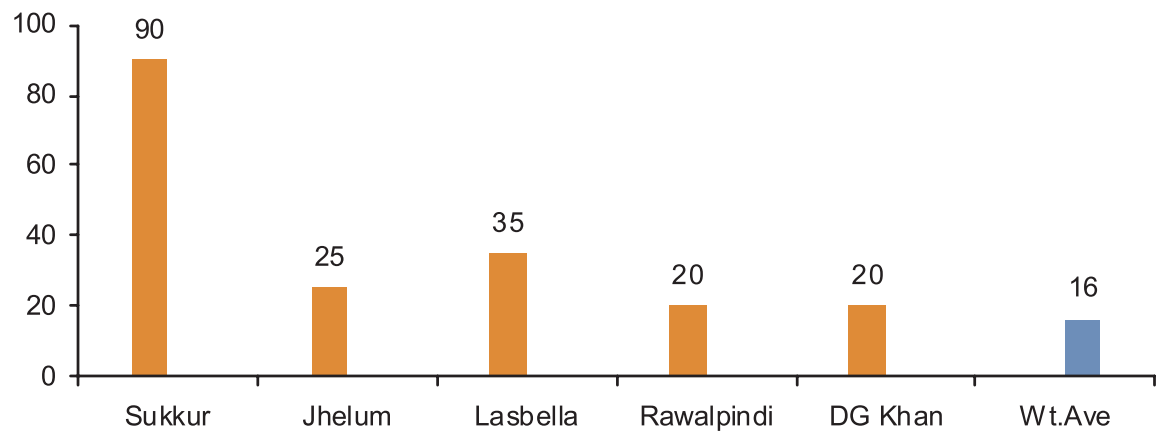

\section{Level of Knowledge about Post Natal Care}

An overwhelming majority (almost all) of women in five districts showed a positive attitude towards Post Natal Care. At the baseline approximately half of the women in 5 districts did not think that a women need postnatal care. Now it is universally thought that a woman need post natal checkup. 
Figure 8: Attitude towards need for PNC

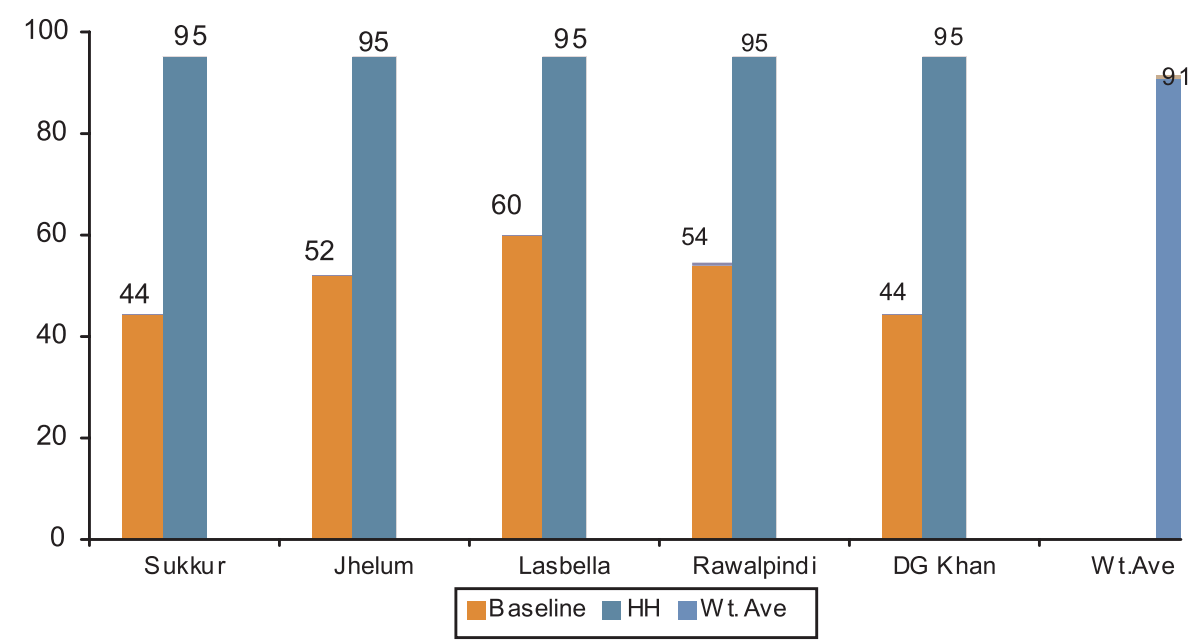

On the other hand majority of women were not aware how soon after delivery a women should go for a postnatal checkup. One-fifth women in District Jhelum and Rawalpindi, less than a third in DG Khan and no one in Lasbella had thought postnatal care should be carried out within 24 hours of delivery. Interestingly more than half women in District Sukkur knew about the correct time when a woman should receive PNC. As the overall average is very low $(13 \%)$, this is a potential area for local NGOs/CBOs to work upon, in 5 districts, especially in District Lasbella.

\section{Figure 9: Knowledge about PNC within 24 hours of Delivery}

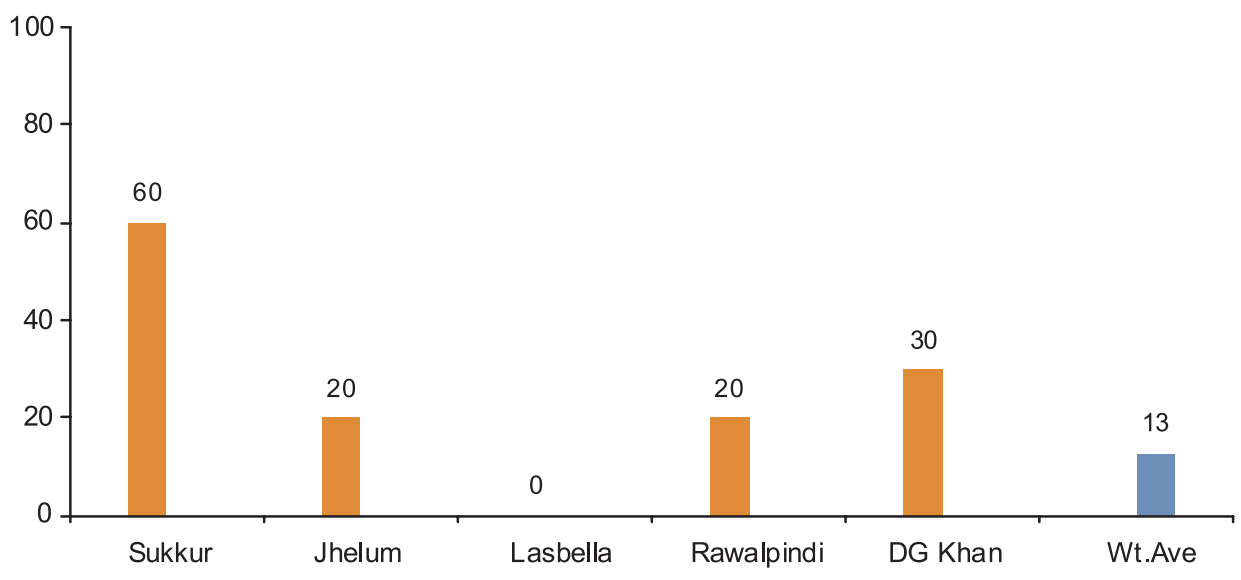

Majority of women in 5 districts thought that women should go to a private hospital/clinic and DHQ/THQ for postnatal care. A few of them also preferred LHW for PNC. 
Table: Percent women responding for appropriate place for post natal checkup

\begin{tabular}{lcc}
\hline \multicolumn{1}{c}{ Where should a woman go for postnatal check up? } & $\mathrm{N}$ & Percent of Cases \\
\hline LHW & 12 & $13.8 \%$ \\
TBA/Dai & 5 & $5.7 \%$ \\
BHU/RHC/Dispensery/MCH Center & 8 & $9.2 \%$ \\
DHQ/THQ & 42 & $48.3 \%$ \\
Pvt. clinic/hospital & 48 & $55.2 \%$ \\
Midwife & 2 & $2.3 \%$ \\
Nurse/LHW & 5 & $5.7 \%$ \\
Total & $95^{*}$ & $100 \% *$ \\
\hline
\end{tabular}

${ }^{*}$ Multiple responses were allowed

\section{Level of Knowledge about Newborn Care}

Less than half of the women in 5 districts showed a satisfactory knowledge regarding newborn care soon after delivery. As there were no baseline estimates available, we can only comment on current level of awareness. Weighted average for 5 districts is $41 \%$. Rawalpindi and Lasbella are below the aggregate weighted average.

Almost all women in Sukkur district responded correctly that breast-feeding should be initiated within 30 minutes of delivery while $65 \%$ in DG Khan and $45 \%$ in Jhelum responded correctly. This aspect needs emphasis especially for District Rawalpindi and Lasbella.

Figure 10: Knowledge about 1st breast feed within 30 minutes of delivery

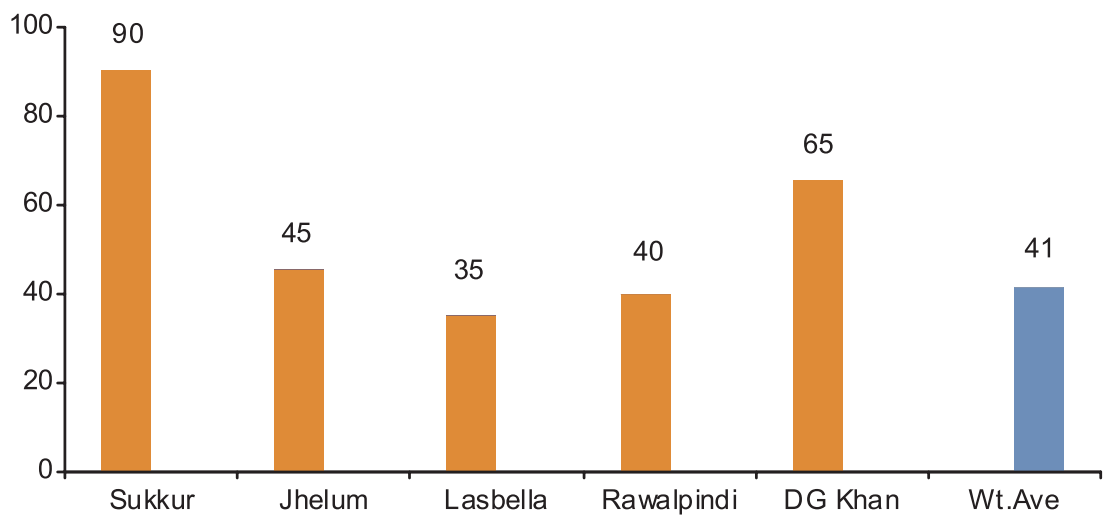


Figure 11: Knowledge about 1st bath after 6 hours

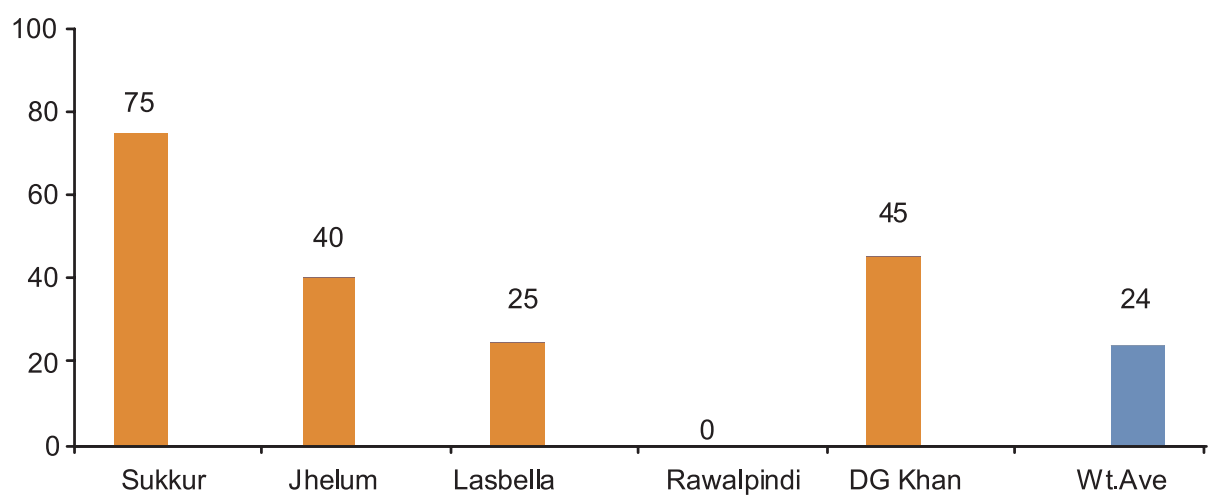

It is important for the mother to know that the first bath to the newborn should be given after 6 hours. Because the newborn acclimatizes the temperature changes from womb of mother and outside environment during this period. Any sudden temperature change may cause hypothermia to the neonate and would also be hazardous for the delicate skin. Majority of respondents in 5 districts were not aware that how long after birth should a newborn be given the first bath. Although majority of women in District Sukkur knew that first bath be given after 6 hours, less than half in Jhelum, DG Khan and only a fourth of women in Lasbella were aware about this fact. No women, out of 19, responded correctly in the union council of Rawalpindi. This points towards the need to continue community awareness efforts regarding newborn care practices, especially in Rawalpindi, Jhelum and Lasbella districts.

Cutting the umbilical cord of the baby with new blade and to tie the cord with new thread are the important practices to avoid Tetanus Neonatorum. Majority of women across five districts were aware about safe practices in this regard. Use of new blade needs to be stressed in Rawalpindi district 
Figure 12: Level of Knowledge about Newborn Care

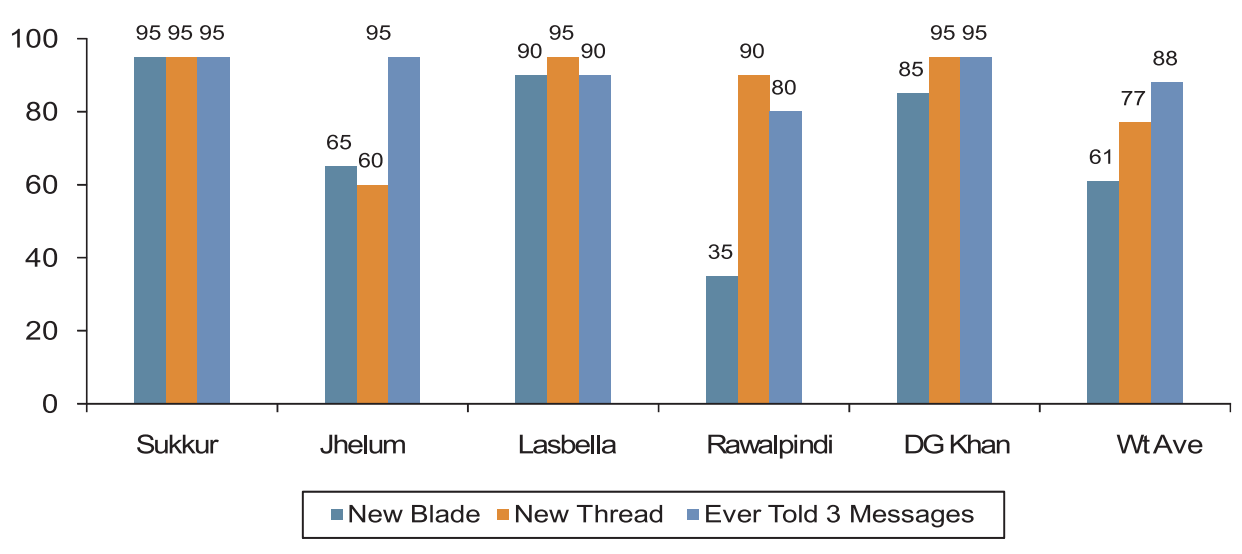

\section{Level of Knowledge about 3 or more danger signs (Pregnancy, Delivery, Postnatal, and Newborn)}

It is also important for a woman to know about abnormal pregnancy besides normal pregnancy. There are some important danger signs, which point towards underlying abnormalities during pregnancy, delivery process, and postnatal period and for newborn baby. Baseline knowledge of women for these indicators was generally low and majority was unaware of 3 or more danger signs regarding these four areas. Weighted average is lowest for knowledge of postnatal danger signs (8\%). DG Khan, Jhelum and Lasbella reported even below this aggregate weighted average. The findings show, overall a mixed picture across five districts. There was a progress in positive direction for all indicators in District Sukkur although awareness about postpartum danger signs needs to be emphasized. District Jhelum showed definite progress for pregnancy and newborn areas but very little for other two areas. The knowledge of women regarding danger signs has not shown an improvement in Lasbella. It is important to continue awareness efforts for ANC and childcare especially in Districts Lasbella, Rawalpind and DG Khan. Delivery and PNC needs emphases across all districts. For district Lasbella a review of strategy would be needed. 
Figure 13: Knowledge of 3 or more danger signs during pregnancy

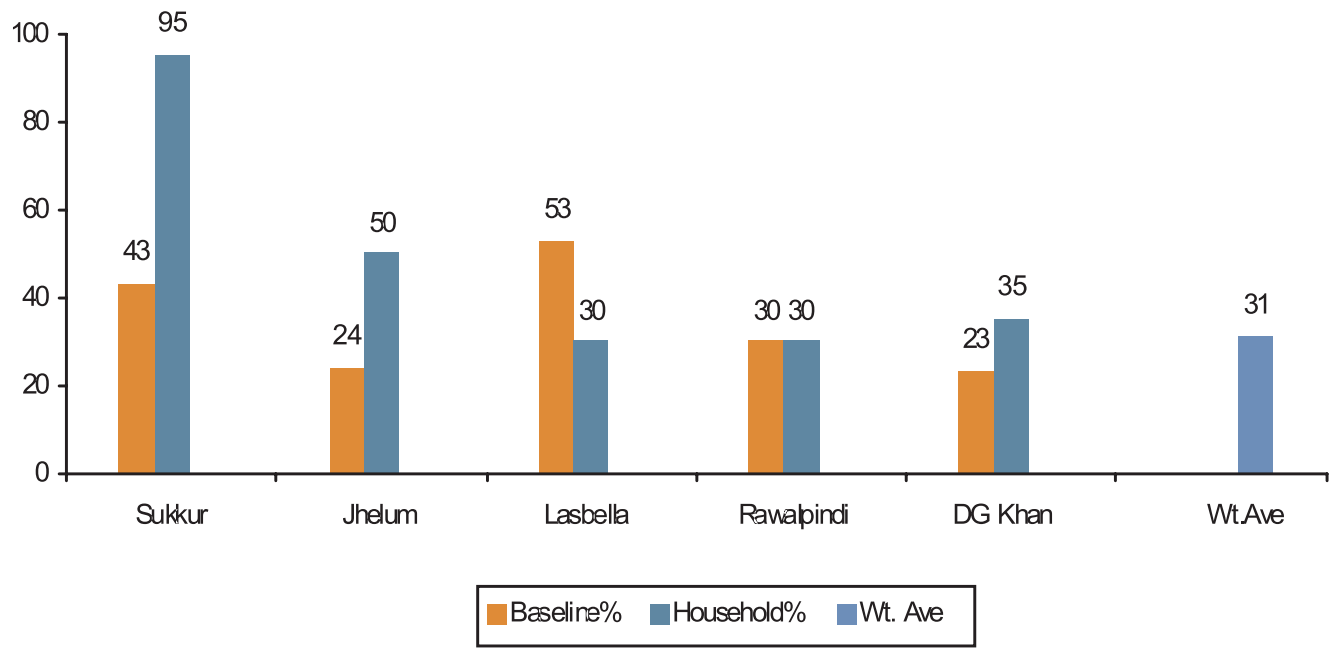

Figure 14: Knowledge of 3 or more danger signs during delivery

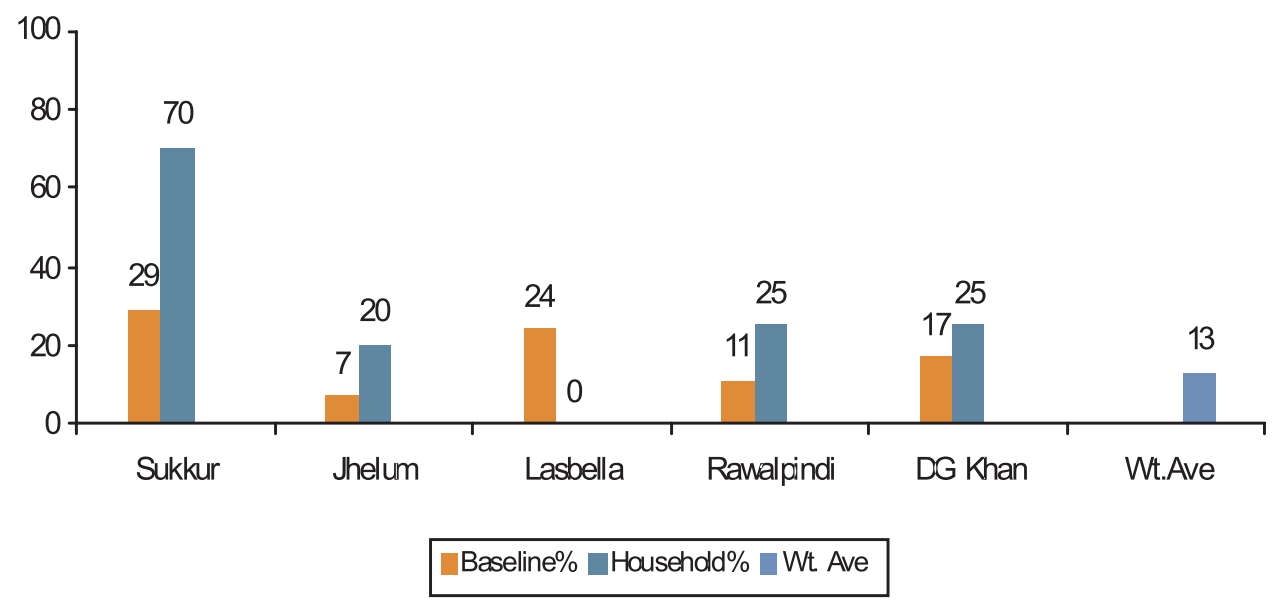

Figure 15: Knowledge of 3 or more danger signs during postpartum period

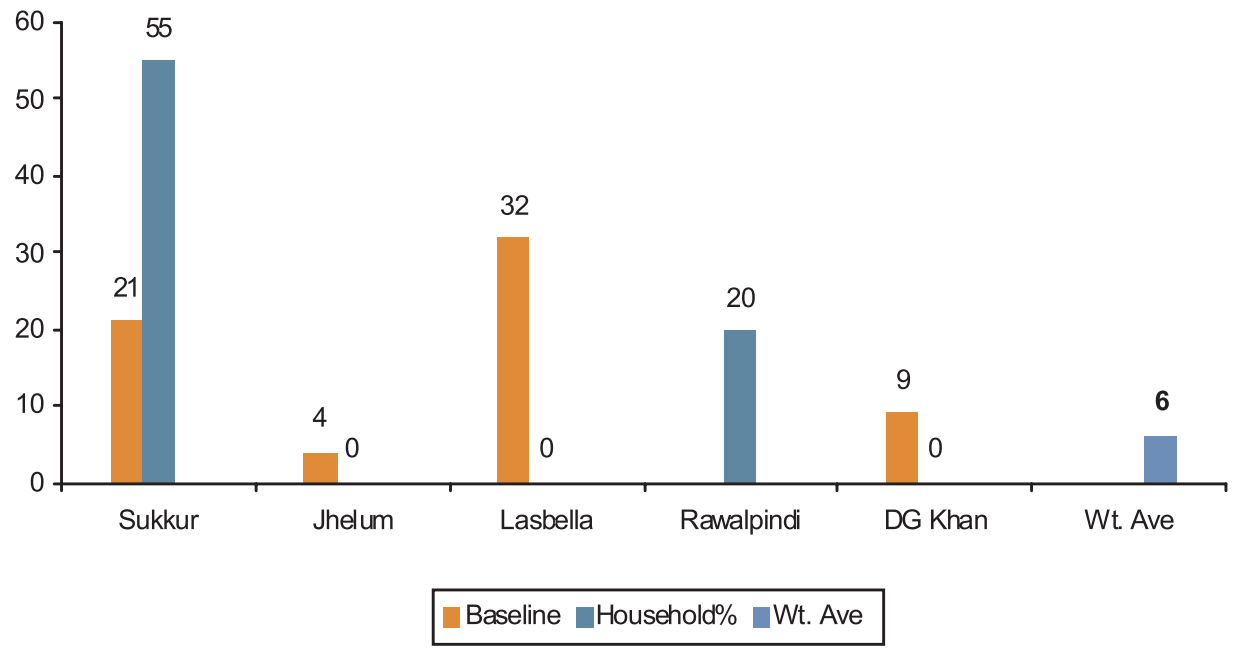


Figure 16: Knowledge of 3 or more danger signs in newborns

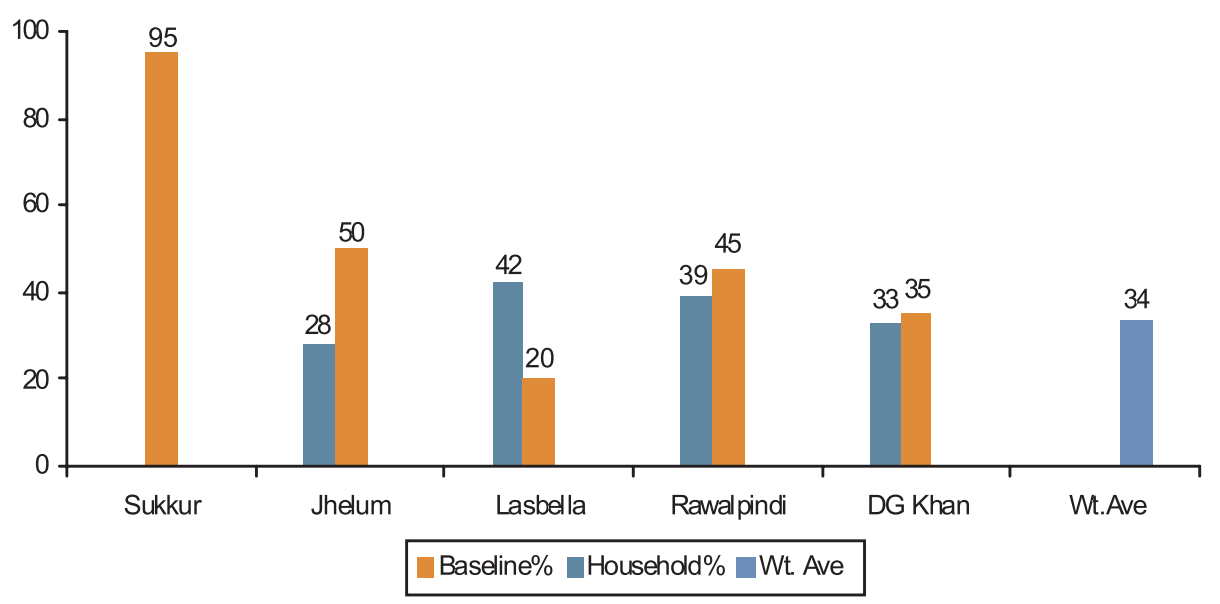

Overall the women most frequently pointed out that severe abdominal pain, vaginal bleeding and severe vomiting were the complications during pregnancy for which it is necessary to seek medical advice while ante partum hemorrhage (bleeding before labour began), excessive vaginal bleeding and premature rupture of membranes were most mentioned complications during delivery. For postnatal period, most frequently mentioned complications were excessive vaginal bleeding, high fever and offensive (foul) discharge from vagina while for newborn, fever, fits, jaundice and blue skin color (cyanosis) were the most frequently mentioned complications worthy to seek medical treatment.

\section{Level of belief that one or more danger signs do not require medical help}

Not only the correct knowledge with regards to $\mathrm{MNH}$ issues is important, it is also pertinent to know about the wrong practices, which a women living in the community have to avoid. A small proportion of interviewed women responded that they would not seek medical treatment for some of the danger signs during pregnancy, natal and postnatal periods and for some signs in newborn. Although less than a quarter of women felt about one or more of danger signs unworthy of medical treatment, this point towards prevalence of wrong knowledge in the communities. Wrong knowledge with regards to pregnancy care and delivery care is more pronounced. Wrong knowledge about these four issues in more prevalent in District DG Khan and Rawalpindi followed by Jhelum and Sukkur. 
Local NGOs need to discuss more deeply with women regarding need to seek medical help in case of these danger signs.

Figure 17: Belief that 1 or more danger signs(Pregnancy, Delivery, Postpartum, Newborn) don't require medical help

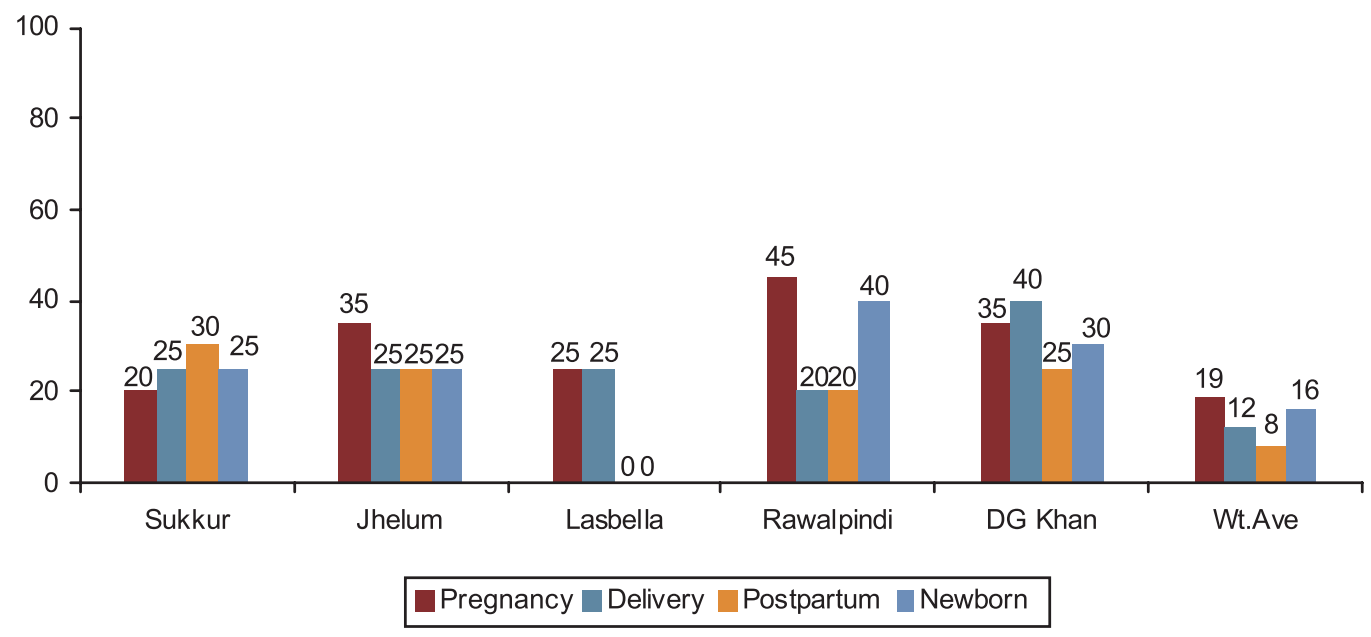




\section{Conclusions and Recommendations:}

Overall findings of community assessment in five districts suggest that beliefs, attitudes and knowledge of married women regarding maternal and newborn issues has improved over time. However there are some knowledge gaps especially in the areas of postnatal and newborn care. Women's knowledge of danger signs (pregnancy, delivery, postnatal and newborn), breastfeeding practices and delaying first bath need to be enhanced. It is obvious that attitudes regarding most of the $\mathrm{MNH}$ issues across five districts are positive but there are gaps regarding correct knowledge. Out of five districts awareness of women in Sukkur seems better than in other districts. This could be due to the fact that all messages in Sukkur were given in local language (Sindhi) compared to other areas where usually Urdu language is used. Community awareness program in Lasbella needs to improve the previous strategy. This can be achieved by more in depth discussions with women of the area and involving men in the campaign. 



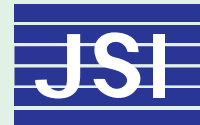

JSI Research \& Training Institute, Inc.

CA \# 36098 project is funded by the United States Agency for International Development and implemented by JSI Research \& Training Institute, inc.

in conjunction with Aga Khan University, Contech International, Greenstar Social Marketing, JHU-

CCP, PAVHNA, Population Council, Save the Children USA 